\title{
Assessing the Tongzhi Label: Self-Identification and Public Opinion
}

Holning Lau, BA, JDa, Geoffrey Yeung, BBA, LLB, PCLL' , Rebecca L. Stotzer, MSW, MA, PhD', Charles Q. Lau, PhD, MS' ${ }^{d}$, and Kelley Loper, LLM, BA

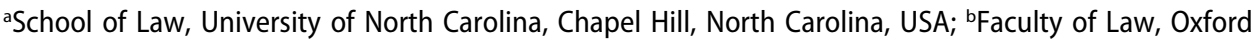
University, Oxford, UK; 'Myron B. Thompson School of Social Work, University of Hawai'i, Honolulu, Hawai'i, USA; dSurvey Research Division, RTI International, Research Triangle Park, North Carolina, USA; eFaculty of Law, University of Hong Kong, Hong Kong, China

\begin{abstract}
Tongzhi is one of several Chinese terms that refer to individuals who are attracted to the same sex. Using data from two different surveys in Hong Kong, this research note examines how the term tongzhi coexists with other terms. We investigate the prevalence of self-identification as tongzhi, and we explore the extent to which using the term tongzhi influences public attitudes toward gay people and gay rights. Activists began popularizing the term tongzhi in the late 1980s, but less than one third of the participants in our 2008 survey of sexual orientation minorities $(n=728)$ described themselves as tongzhi. Using a split-ballot experiment in a 2013 public opinion poll ( $n=831$ ), we found that attitudes toward gay people and gay rights were not significantly impacted by whether questions were phrased in terms of tongzhi or the main alternative term tongxinglianzhe. We discuss how our findings can enrich understandings of earlier research and illuminate avenues for future study.
\end{abstract}

\section{KEYWORDS}

China; gay; Hong Kong; identity; lesbian; public opinion; tongzhi

The language of identification can influence sexual minorities' sense of self and the way that they are perceived by others. In English-speaking parts of the world, for example, numerous terms refer to individuals who are attracted to the same sex, but some terms are preferred over others (Glazer, 2010). As an act of self-definition, an individual might identify as gay while rejecting alternative terms such as homosexual. These labels also influence public opinion. Some studies in the United States have shown that referring to "gays and lesbians," as opposed to "homosexuals," increases the public's acceptance of this minority group and support for their rights (Hechkopf, 2010; Saad, 2005).

Of course, English-speaking societies are not the only ones to have multiple ways of referring to people who are attracted to the same sex. In culturally Chinese societies, tongzhi (同志) is one of the terms that serve this purpose. 
In Chinese, the term tongzhi is used as an alternative to other terms, such as tongxinglianzhe (同性戀者), which also appear frequently in public discourse to denote individuals with same-sex attraction. Even in English texts, some writers have adopted the transliteration tongzhi to refer to Chinese individuals who are attracted to the same sex (e.g., Chou, 1997; To, 2003). ${ }^{1}$

To the best of our knowledge, there has not been published quantitative research on the term tongzhi's usage and significance. This research note begins to fill that gap. Drawing on data from two surveys, this note examines how the term tongzhi coexists with other terminological options in the Hong Kong context. By shedding light on how the term tongzhi operates, we hope to help researchers make better-informed decisions concerning language. These decisions can arise at various stages of research, ranging from the solicitation of research participants (e.g., should participants be referred to as tongzhi?) to the development of survey instruments (e.g., would the term tongzhi bias responses?).

The remainder of this research note unfolds in four parts. It begins by providing readers with a primer on gay activists' appropriation of the term tongzhi. This note then presents survey data from sexual orientation minorities $^{2}$ in Hong Kong to investigate the prevalence of self-identification as tongzhi and to examine whether self-identified tongzhis also adopt or eschew alternative identifiers. Next, this note shifts the focus to the general public. Using data from a public opinion survey in Hong Kong, we examine the extent to which using the term tongzhi influences public attitudes toward gay people and gay rights. Finally, this note will conclude by discussing how our data can enrich understandings of earlier research as well as illuminate avenues for future study.

\section{Development of the term tongzhi}

The Chinese characters for tongzhi translate literally as "same will." The term has a substantial history in the Chinese language. Sun Yat-sen, a revolutionary leader in the early 20th century whom many honor as the founder of modern China, famously stated in his will: "Geming shangwei chenggong, tongzhi rengxu nuli?" ("The revolution has not yet succeeded; comrades we must struggle still!"; (Martin, 2003, p. 23). The Chinese Communist Party later popularized using tongzhi to mean "comrade" when referring to fellow party members and compatriots. The use of tongzhi in this old political context has, however, fallen out of favor since the political and economic reforms of the 1980s in the People's Republic of China (A. D. Wong, 2005).

Meanwhile, some gay activists appropriated the term tongzhi as their identity label. Michael Lam, a cultural critic and writer in Hong Kong, claimed that he first used tongzhi as an inside joke among friends in his local articles during the mid-1980s (Lam, 2003). The term gained popularity 
in Hong Kong when Edward Lam, curator of the first Hong Kong Lesbian and Gay Film Festival, used tongzhi in the festival's Chinese title in 1989 (Chou, 1997; Lam, 2003; A. D. Wong, 2005). Over time, gays' and lesbians' appropriation of the term tongzhi spread beyond Hong Kong to other parts of Greater China and to Chinese diasporic communities around the world (Ho, 2008).

Activists adopted the word tongzhi because they sought an alternative to the existing identificatory terms for referring to individuals who experience samesex desires. By the late 1980s in Hong Kong, tongxinglianzhe (同性戀者) and gay (sometimes transliterated into the Chinese character 基, i.e., gei) were the most widely used terms for referring to individuals with same-sex desires (Chou, 1997). Both of these terms had derogatory connotations at the time.

Tongxinglianzhe is often understood to be the Chinese counterpart to the English term homosexual, although the Chinese characters in tongxinglianzhe can be translated more literally as "same-gender loving person." Like the English word homosexual, tongxinglianzhe has been used widely in legal and medical discourses. As such, commentators have suggested that tongxinglianzhe has a history of carrying connotations of pathology and illness (A. D. Wong, 2008; D. Wong, 2011).

Like tongxinglianzhe, the Cantonese transliteration of "gay" also has had negative connotations. While the English term gay is often associated with pride and has a literal meaning of happiness, those aspects were diminished and perhaps lost in transliteration. This is apparent in how Cantonese speakers use the transliteration gei in collocations with other words to produce derogatory meanings (A. D. Wong, 2008; D. Wong, 2011). For example, gaau gei (搞基) in Cantonese refers to "engaging in homosexuality," where gaau is a verb that usually conveys involvement in an act that is socially disapproved. Meanwhile, gei lou (基佬) refers to homosexual men, in which lou is a suffix usually attached to men of lower classes.

Both the term tongxinglianzhe and the transliteration of "gay" were used extensively in local media coverage of the 1980 MacLennan Incident, which concerned the mysterious death of a young male police inspector in Hong Kong suspected to have engaged in sexual acts with a male prostitute (Chou, 1997). The incident, for the first time, stirred intense discussions about homosexuality in Hong Kong. In public discourse from the MacLennan Incident up to the decriminalization of "buggery" (i.e., anal intercourse) in 1991, tongxinglianzhe and the Cantonese transliteration of "gay" came to be associated with the negative image of homosexual men "engaging in illegal, immoral and indecent sexual behavior" (D. Wong, 2011, p. 156). Against this backdrop, activists adopted a new term, tongzhi, as a more positive identity label that they perceived as carrying connotations of respect, equality, and resistance (A. D. Wong, 2005). 
In addition to using the term tongzhi to avoid the negative connotations of alternative options, some individuals prefer the term tongzhi because of its indigeneity (Chou, 1997; D. Wong, 2011). The transliteration of the word gay from English clearly has foreign origins. Tongxinglianzhe also lacks indigeneity in that it refers to homosexuals generally, including homosexuals from diverse cultural contexts. In contrast, commentators often use the word tongzhi to refer exclusively to individuals in Chinese contexts. The word tongzhi conveys cultural specificity, helping to cultivate a shared positive identity and sense of solidarity among sexual orientation minorities in Chinese contexts and, to some extent, other sexual minorities in Chinese contexts including transgender people (D. Wong, 2011). Some commentators also deliberately use the word tongzhi, even in English texts, to remind audiences that the experiences of sexual minorities in Chinese settings sometimes differ substantially from the experiences of their counterparts in other cultural contexts (e.g., Chou, 1997).

Over the years, some activists have attempted to use the term tongzhi as an umbrella term covering all sexualities outside the mainstream and all people who dissent from heteronormativity, bringing the term's meaning closer to that of the reappropriated term queer in English; however, such efforts have waned since the late 1990s (King, 2001). Commentators believe that the public usually understands tongzhi to refer only to individuals who desire same-sex partners (Chou, 1997; King, 2001).

While the reasons for appropriating the term tongzhi are relatively clear, other aspects of the term are more opaque. For example, there is very little literature on the extent to which sexual orientation minorities self-identify with the term. In a qualitative study based on 37 interviews of sexual orientation minorities in Hong Kong, A. D. Wong (2008) found that interviewees who were activists preferred the term tongzhi, but their non-activist counterparts did not. Beyond A. D. Wong's research, we are not aware of any other existing empirical studies on the prevalence of self-identification as tongzhi. This research note presents survey data to address that information gap.

This research note also sheds light on how the general public responds to the term tongzhi. Surely, activists appropriated the term to construct a positive identity for sexual orientation minorities. The social understanding of language is, however, fluid. In a content analysis of a popular Hong Kong newspaper, A. D. Wong (2005) found that the term tongzhi was often used derisively. His research showed that opponents of homosexuality can "reappropriate" the term tongzhi, using it in ways that activists did not intend. Meanwhile, it is possible that alternative terms such as tongxinglianzhe have shed some of their negative connotations as Hong Kong society becomes more accepting of sexual orientation diversity. Using survey data, this research note will examine whether the general public responds differently to the terms tongzhi and tongxinglianzhe. 


\section{Self-identification as tongzhi}

In this part of the research note, we investigate the prevalence of selfidentification as tongzhi among people in Hong Kong who say they are not heterosexual. Our analysis is based on an online survey of Hong Kong individuals who self-identify as having a sexual orientation other than heterosexual. The survey asked respondents to describe themselves by selecting one or more options from a list of self-identification labels, and tongzhi was one of the options. The survey also asked respondents about their demographic characteristics and experiences as sexual orientation minorities in Hong Kong. Two authors of this research note conducted this brief and anonymous Internet survey in 2008. Institutional Review Board (IRB) approval was received prior to fielding the survey.

The study primarily used a snowball sampling strategy for recruitment. Although snowball sampling does not generate a random sample, it is a well-accepted methodology for accessing stigmatized and hidden populations (Bucher \& Raess, 2007; Weiss, 2007). Snowball sampling recruits respondents through social networks. It is thus a sampling method that risks excluding "isolates" who are insufficiently connected to such networks. Increasing sample size and diversifying the channels of survey distribution help to reduce these risks (Atkinson \& Flint, 2001; Southern et al., 2008). Accordingly, the 2008 study recruited a large sample through four different channels.

First, the research team solicited survey participants via e-mail. The team circulated a bilingual (Chinese and English) solicitation message on various Listservs for sexual minority community groups. The solicitation was e-mailed in two waves spaced 6 months apart. Along with asking sexual orientation minorities to take the online survey, the solicitation asked recipients to pass the solicitation to other sexual orientation minorities. Second, the research team forwarded the solicitation to self-identified sexual orientation minorities on two social networking websites; one Web site catered to individuals seeking sexual activity, while the other catered to individuals seeking platonic and professional relationships. Third, the research team posted the solicitation on Internet bulletin boards and blogs that target sexual orientation minority readers. Fourth, the solicitation was distributed as a postcard at Hong Kong's annual International Day Against Homophobia March and at bars frequented by sexual orientation minorities.

These recruitment efforts generated 792 responses from individuals in Hong Kong. Our analysis sample consists of 728 respondents after excluding 26 respondents who were under 18 years old, 35 respondents who did not report their age, and three respondents who did not answer the survey's question about identity labels. The age range of the analysis sample was 18-72 $(M=27.3, S D=8.9)$. Of those who responded to demographic questions, $43 \%$ identified as male, $57 \%$ as female, and $0.1 \%$ identified as 
"other" (e.g., transgender). The highest level of educational attainment for $39 \%$ of respondents consisted of secondary education or less; another $9 \%$ held associate degrees; $38 \%$ held bachelor's degrees; and 14\% held graduate degrees. Eighty-four percent of respondents identified as ethnic Chinese. Overall, the sample reflected the diverse segments of Hong Kong's general population. On average, however, the respondents were younger than the general public and had completed more formal education. The sample also included an overrepresentation of Whites (Caucasians). Of the survey respondents who reported their race, $10 \%$ identified as White. In contrast, only $1 \%$ of the general public identified as White in Hong Kong's 2011 census (Census and Statistics Department, 2012).

The online survey was conducted in both Chinese and English. Among the survey participants, 543 individuals (75\%) took the Chinese version of the survey, and 185 (25\%) took the English version. A majority (52\%) of the English-language participants identified as ethnic Chinese. Early in the survey, the respondents, all of whom said they were not heterosexual, were presented a list of identification labels and asked to check all the labels that they would use to describe themselves. Table 1 shows the 11 identification labels that the survey presented to each respondent, in the order that they were presented. In each row, the Chinese and English labels have been paired with their approximate counterparts. We included the transliterated term tongzhi as an option in the English version of the survey, so that we could examine whether the term tongzhi had crossed over from Chinese to English. Meanwhile, the Chinese version of the survey included a few English words. The Chinese-language survey kept the word gay in English, as opposed to using the character 基, because the negative connotations of that Chinese character were so strong that we thought respondents would be unlikely to select it. To be consistent, the Chinese version of the survey kept the word lesbian in English and also listed les, which is a common abbreviation used in Hong Kong.

The survey's findings provide a helpful snapshot of tongzhi self-identification in Hong Kong. As of 2008, tongzhi was a self-identification that had been adopted by a segment of sexual orientation minorities in Hong Kong. The term had not been adopted universally. Among Chinese-language respondents, 30\% selected the term tongzhi. Among English-language respondents, $12 \%$ selected the transliteration of tongzhi as a self-identification label, demonstrating that the term had crossed over from Chinese to the English language in Hong Kong. Among Chinese- and English-language respondents combined, $25 \%$ selected tongzhi. In contrast to the fact that only a minority of respondents selected tongzhi, 61\% of all respondents selected "homosexual" (同性戀), and 64\% selected either "gay" or "lesbian."

Interestingly, for respondents who did choose tongzhi, the label was selected in addition to other terms. Among respondents who selected 
Table 1. Self-identification labels selected by sexual orientation minorities in Hong Kong.

\begin{tabular}{|c|c|c|c|c|}
\hline \multicolumn{2}{|l|}{ English Survey } & \multicolumn{2}{|c|}{ Chinese Survey } & \multirow{2}{*}{$\begin{array}{l}\text { Combined } \\
\text { Participants }\end{array}$} \\
\hline $\begin{array}{l}\text { Response } \\
\text { Options }\end{array}$ & Participants & $\begin{array}{l}\text { Response } \\
\text { Options }\end{array}$ & Participants & \\
\hline Homosexual & $52 \%$ & 同性戀 & $63 \%$ & $61 \%$ \\
\hline Bisexual & $18 \%$ & 雙性戀 & $22 \%$ & $21 \%$ \\
\hline Gay & $\begin{array}{l}47 \% \\
\text { ( } 68 \% \text { of male } \\
\text { respondents) }\end{array}$ & Gay & $\begin{array}{l}23.9 \% \\
\text { ( } 63 \% \text { of male } \\
\text { respondents) }\end{array}$ & $\begin{array}{l}30 \% \\
\text { (65\% of male } \\
\text { respondents) }\end{array}$ \\
\hline $\begin{array}{l}\text { Man who has sex with } \\
\text { men (MSM) }\end{array}$ & $\begin{array}{l}24 \% \\
\text { (37\% of male } \\
\text { respondents) }\end{array}$ & $\begin{array}{l}\text { 與男性有性關係 } \\
\text { 的男人(MSM) }\end{array}$ & $\begin{array}{l}15 \% \\
\text { (40\% of male } \\
\text { respondents) }\end{array}$ & $\begin{array}{l}17 \% \text { ( } 39 \% \text { of male } \\
\text { participants) }\end{array}$ \\
\hline Lesbian & $\begin{array}{l}19 \% \\
\text { ( } 51 \% \text { of female } \\
\text { respondents) }\end{array}$ & Lesbian (les) & $\begin{array}{l}43 \% \\
\text { (66\% of female } \\
\text { respondents) }\end{array}$ & $\begin{array}{l}37 \% \\
\text { (64\% of female } \\
\text { participants) }\end{array}$ \\
\hline $\begin{array}{l}\text { Woman who has sex } \\
\text { with women (WSW) }\end{array}$ & $\begin{array}{l}9 \% \\
\text { (24\% of female } \\
\text { respondents) }\end{array}$ & $\begin{array}{l}\text { 與女性有性關係 } \\
\text { 的女人(WSW) }\end{array}$ & $\begin{array}{l}21 \% \\
\text { (32\% of female } \\
\text { respondents) }\end{array}$ & $\begin{array}{l}18 \% \\
\text { (31\% of female } \\
\text { participants) }\end{array}$ \\
\hline Tongzhi & $12 \%$ & 同志 & $30 \%$ & $25 \%$ \\
\hline Women-loving woman & $\begin{array}{l}15 \% \\
\text { (40\% of female } \\
\text { respondents) }\end{array}$ & $\begin{array}{l}\text { 會愛上女人的女 } \\
\text { 人 }\end{array}$ & $\begin{array}{l}37 \% \\
\text { (58\% of female } \\
\text { respondents) }\end{array}$ & $\begin{array}{l}32 \% \\
\text { (55\% of female } \\
\text { respondents) }\end{array}$ \\
\hline Lala & $\begin{array}{l}3 \% \\
\text { (8\% of female } \\
\text { respondents) }\end{array}$ & 拉拉 & $\begin{array}{l}12 \% \\
\text { (19\% of female } \\
\text { respondents) }\end{array}$ & $\begin{array}{l}10 \% \\
\text { (17\% of female } \\
\text { respondents) }\end{array}$ \\
\hline Same-gender loving & $20 \%$ & 與同性相愛之人 & $39 \%$ & $34 \%$ \\
\hline Queer & $16 \%$ & $\begin{array}{l}\text { 酷兒 / 酷異 / 攣 } \\
\text { (Queer) }\end{array}$ & $14 \%$ & $15 \%$ \\
\hline
\end{tabular}

Note. Data come from an online survey of sexual orientation minorities in Hong Kong conducted in 2008 (English survey: $n=185$; Chinese survey: $n=543$; combined: $n=728$ ).

tongzhi, almost all (97\%) of them also identified as "gay," "lesbian," "bisexual” (雙性戀) and/or “homosexual” (同性戀). Only 2\% of respondents selected tongzhi exclusively. This scenario contrasts with the increasing mainstream belief in the United States and some other English-speaking societies that individuals who identify as "gay" often completely eschew the term "homosexual" as a stigmatized identity (Peters, 2014). Experience in contexts such as the United States might tempt researchers to understand the term tongzhi as an exclusionary substitute for other terms, but our findings suggest that this approach should be avoided.

\section{Impact on public opinion}

This section of the research note queries whether using the term tongzhi as opposed to tongxinglianzhe impacts public opinion about gay people and gay rights. Our analysis is based on a 2013 telephone survey that three of this research note's authors designed. After receipt of IRB approval, the survey was conducted by the Social Sciences Research Center (SSRC) at the University of Hong Kong. 
SSRC interviewed 850 people age 18 and over by telephone in June 2013. The survey was based on a probability sample of landline telephone numbers in Hong Kong. Interviews took 8 minutes to complete on average $(S D=3.4$ minutes), and almost all interviews (98\%) were conducted in Cantonese, which is consistent with language patterns in Hong Kong. The remainder was conducted in English. The cooperation rate was 78\% (AAPOR Cooperation Rate 2), and the overall response rate for the survey was $15 \%$ (AAPOR Response Rate 4).

In this research note, we restrict the sample to the 831 interviews that were conducted in Cantonese. We do not analyze the surveys conducted in English because the term tongzhi was not used in those interviews. We focus on seven items that measure attitudes toward gay people in Hong Kong. For all seven items, we randomly assigned each respondent to one of two conditions. One half of the respondents were randomly assigned questions phrased in terms of tongzhi; the other half were assigned questions phrased in terms of tongxinglianzhe (and tongxinglian for brevity). We designed this experiment to investigate the impact of language on attitudes toward gays and lesbians.

The first item asked "How accepting are you of [tongzhi/tongxinglianzhe]?" and had response options of "very," "moderately," "a little," and "not at all accepting." The next six items were "A person's sexual orientation does not affect whether I accept that person"; "It does not matter to me whether my friends are [tongzhi/tongxinglian] or straight"; "Parents should love their children regardless of whether their children are [tongzhi/tongxinglian] or straight"; "[tongzhi/tongxinglianzhe] make me nervous"; "[tongzhi/tongxinglianzhe] are immoral"; "[tongzhi/tongxinglianzhe] should be avoided whenever possible." Response options were "completely agree," "somewhat agree," "neutral," "somewhat disagree," and "completely disagree." We chose these items based on existing scales (e.g., Morrison \& Morrison, 2003; Wright, Adams, \& Bernat, 1999) because of their relevance to Hong Kong.

In Table 2, we show the impact of using the term tongzhi versus tongxinglianzhe on attitudes toward gays and lesbians. According to chi-square tests, there are no statistically significant differences between the two terms in any of the items.

After interviewers asked respondents about their attitudes toward gays and lesbians, they asked: "Do you agree or disagree that Hong Kong should have a law that protects people from being discriminated against because of their sexual orientation?" Again, the response options were "completely agree," "somewhat agree," "neutral," "somewhat disagree," and "completely disagree." This question did not use the terms tongzhi or tongxinglianzhe; however, we investigate whether exposing respondents to the respective terms in preceding questions primes respondents in a way that impacts their opinions on gay legal rights. To prime an individual is to stimulate that individual's retrieval of information or feelings that he or she already 
Table 2. Attitudes toward sexual orientation minorities, by terminology used (percentages shown).

A. How accepting are you of [tongzhi/tongxinglianzhe]?

你有幾接受 [同志/同性戀者]?

\begin{tabular}{lcccc}
\hline & Tongzhi & Tongxinglianzhe & Entire Sample & $\mathrm{X}^{2}$ test \\
\hline Very accepting & 22 & 22 & 22 & $\mathrm{x}^{2}(3)=0.61$ \\
Moderately accepting & 35 & 37 & 36 & $\mathrm{p}=.89$ \\
A little accepting & 20 & 20 & 20 & \\
Not at all accepting & 23 & 21 & 22 & \\
\hline
\end{tabular}

B. A person's sexual orientation does not affect whether I accept that person 我接受唔接受一個人, 唔係基於佢嘅性傾向

\begin{tabular}{lcccc}
\hline & Tongzhi & Tongxinglianzhe & Entire Sample & $\mathrm{X}^{2}$ test \\
\hline Completely Agree & 57 & 54 & 56 & $\mathrm{X}^{2}(4)=1.61$ \\
Somewhat Agree & 18 & 18 & 18 & $\mathrm{p}=.80$ \\
Neutral & 14 & 15 & 15 & \\
Somewhat Disagree & 3 & 4 & 4 & \\
Completely Disagree & 8 & 9 & 8 & \\
\hline
\end{tabular}

C. It does not matter to me whether my friends are [tongzhi/tongxinglian] or straight 我嘅朋友係 $[$ 同志/同性戀]定係異性戀對我沒有影響

\begin{tabular}{lcccc}
\hline & Tongzhi & Tongxinglianzhe & Entire Sample & $\mathrm{X}^{2}$ test \\
\hline Completely Agree & 67 & 69 & 68 & $\mathrm{x}^{2}(4)=6.08$ \\
Somewhat Agree & 10 & 13 & 12 & $p=.19$ \\
Neutral & 11 & 7 & 9 & \\
Somewhat Disagree & 5 & 4 & 5 & \\
Completely Disagree & 6 & 6 & 6 & \\
\hline
\end{tabular}

D. Parents should love their children regardless of whether their children are [tongzhi/tongxinglian] or straight 無論佢哋嘅子女係 [同志/同性戀] 定係異性戀, 父母都應該愛佢哋嘅子女

\begin{tabular}{lcccc}
\hline & Tongzhi & Tongxinglianzhe & Entire Sample & $\mathrm{X}^{2}$ test \\
\hline Completely Agree & 82 & 85 & 84 & $\mathrm{X}^{2}(4)=1.96$ \\
Somewhat Agree & 11 & 8 & 9 & $p=.74$ \\
Neutral & 5 & 5 & 5 & \\
Somewhat Disagree & 1 & 1 & 1 & \\
Completely Disagree & 2 & 1 & 2 & \\
\hline
\end{tabular}

E. [Tongzhi/Tongxinglianzhe] make me nervous

[同志/同性戀者]會令我緊張

\begin{tabular}{lcccl}
\hline & Tongzhi & Tongxinglianzhe & Entire Sample & $\chi^{2}$ test \\
\hline Completely Agree & 10 & 9 & 9 & $\chi^{2}(4)=1.51$ \\
Somewhat Agree & 14 & 16 & 15 & $p=.83$ \\
Neutral & 14 & 15 & 15 & \\
Somewhat Disagree & 11 & 12 & 11 & \\
Completely Disagree & 51 & 48 & 50 & \\
\hline
\end{tabular}

F. [Tongzhi/Tongxinglianzhe] are immoral

[同志/同性戀者]係唔道德嘅

\begin{tabular}{lcccc}
\hline & Tongzhi & Tongxinglianzhe & Entire Sample & $\mathrm{X}^{2}$ test \\
\hline Completely Agree & 16 & 14 & 15 & $\mathrm{X}^{2}(4)=4.95$ \\
Somewhat Agree & 6 & 7 & 7 & $p=.29$ \\
Neutral & 21 & 17 & 19 & \\
Somewhat Disagree & 12 & 16 & 14 & \\
Completely Disagree & 45 & 45 & 45 & \\
\hline
\end{tabular}

G. [Tongzhi/Tongxinglianzhe] should be avoided whenever possible 盡可能都會避開 [同志/同性戀者]

\begin{tabular}{lcccl}
\hline & Tongzhi & Tongxinglianzhe & Entire Sample & $\chi^{2}$ test \\
\hline Completely Agree & 12 & 9 & 10 & $\chi^{2}(4)=4.79$ \\
Somewhat Agree & 9 & 9 & 9 & $p=.31$ \\
Neutral & 15 & 12 & 13 & \\
Somewhat Disagree & 14 & 13 & 13 & \\
Completely Disagree & 51 & 58 & 54 & \\
\hline
\end{tabular}

Note. Data come from a telephone survey of the Hong Kong adult population conducted in $2013(n=831)$. Sample size varies by item due to item non-response. Percentages may not sum to 100 due to rounding. Sample limited to interviews conducted in Cantonese. Data are unweighted. 
possesses (Tourangeau \& Rasinski, 1988). We examined whether exposing respondents to a particular word-tongzhi or tongxinglianzhe-in previous questions would stimulate respondents to retrieve particular thoughts or feelings about gay people and their rights. For example, if the term tongxinglianzhe has particularly negative connotations, it might stimulate the retrieval of negative stereotypes in someone's mind, resulting in a rejection of gay rights. The chi-square test in Table 3 shows, however, that respondents' support for antidiscrimination legislation to advance gay rights did not differ significantly depending on whether respondents had been exposed to the term tongzhi or tongxinglianzhe in previous interview questions.

In sum, the terminological difference between tongzhi and tongxinglianzhe did not produce any statistically significant differences in people's attitudes toward gay people or gay rights. These findings contrast with research from the United States that compares the terms gay and homosexual. Surveys from the United States have shown that phrasing questions in terms of "homosexuals," instead of "gays and lesbians," is associated with lower rates of accepting gay people in the contexts of employment and military service (Hechkopf, 2010; Saad, 2005). One other study from the United States found that asking about "gay and lesbian couples," as opposed to "homosexual couples," did not affect the overall level of support for marriage or civil unions for same-sex couples, but it affected the intensity of attitudes (McCabe \& Heerwig, 2011).

\section{Research implications}

The findings from the two surveys that we have discussed shed light on how to understand earlier studies and how to think about future research. Our

Table 3. Attitudes toward an anti-discrimination law, by terminology used in previous questions (percentages shown).

Do you agree or disagree that Hong Kong should have a law that protects people from being discriminated against because of their sexual orientation?

請問你同唔同意香港應該有法例保護因性傾向而被歧視嘅市民?

\begin{tabular}{lcccc}
\hline & $\begin{array}{c}\text { Tongzhi used in previous } \\
\text { questions }\end{array}$ & $\begin{array}{c}\text { Tongxinglianzhe used in previous } \\
\text { questions }\end{array}$ & $\begin{array}{c}\text { Entire } \\
\text { Sample }\end{array}$ & $\mathrm{x}^{2}$ test \\
\hline $\begin{array}{c}\text { Completely } \\
\text { Agree }\end{array}$ & 46 & 47 & 47 & $\mathrm{x}^{2}$ \\
$\begin{array}{c}\text { Somewhat } \\
\text { Agree }\end{array}$ & 16 & 17 & 17 & $\begin{array}{l}(4)=4.02 \\
p=.40\end{array}$ \\
$\begin{array}{c}\text { Neutral } \\
\text { Somewhat }\end{array}$ & 21 & 16 & & \\
$\quad$ Disagree & 3 & 5 & 4 & \\
$\begin{array}{c}\text { Completely } \\
\text { Disagree }\end{array}$ & 13 & 15 & 14 & \\
\hline
\end{tabular}

Note. Data come from a telephone survey of the Hong Kong adult population conducted in $2013(n=818)$. Percentages may not sum to 100 due to rounding. Sample limited to interviews conducted in Cantonese. Data are unweighted. 
research supports existing accounts that cast doubt on the popularity of selfidentification with the term tongzhi among individuals in Hong Kong who are not heterosexual (e.g., D. Wong, 2011). While our research cannot speak to the term's popularity after 2008, it appears that statements about the term's popularity as a self-identification label up until 2008 have been overstated. For example, Chou has stated that tongzhi is "the most popular contemporary Chinese word for lesbians, bisexuals, and gay people" (Chou, 2001, p. 27), and this claim has been echoed by other scholars (e.g., Lee, 2003, p. 158). Our survey on self-identification, however, encourages critical reevaluation of such assertions (cf. A. D. Wong, 2008).

Our research also provides some guidance on how to understand existing public opinion data. In the past, surveys about public opinion in Hong Kong have deployed different terms. For example, the Hong Kong government conducted a widely publicized public opinion survey in 2005 concerning gay people and gay rights. Its survey instrument referred to gay people exclusively as tongxinglianzhe (Home Affairs Bureau, 2006). In contrast, a non-governmental organization called Community Business conducted its own public opinion survey in 2011 and 2012. Its survey instrument referred to gay people as tongzhi as well as tongxinglianzhe and tongxinglianrenshi (同性戀人士), which is closely related to the term tongxinglianzhe (Vernon \& Yik, 2012). There are many potential explanations for why these two surveys' findings about public opinion differ, including the substantial time gap between the surveys. Readers familiar with research from the United States about the difference between the terms gay and homosexual might wonder whether the two Hong Kong surveys also produced divergent results partly because of their difference in terminology for gay people. Our research suggests that the change in terminology may not have had as strong an impact as one might predict at first blush.

In terms of the path ahead, future studies could provide more current rates of self-identification with the term tongzhi. There are reasons to believe that the term tongzhi has become a more popular means of self-identification since the 2008 study. For example, the term has become popularized through widespread advocacy campaigns that use the term tongzhi, and some popular celebrities have embraced the term. Use of the term tongzhi in positive news reports, such as mainstream media coverage of the Hong Kong Pride Parade (e.g., Chan \& Poon, 2013), may also have further popularized the term tongzhi. At the same time, it is possible that alternative terms such as tongxinglianzhe and gay have shed negative connotations over the years and have therefore also become more widely embraced. In particular, individuals may possibly be more willing to self-identify as gay now because the gay label has been integrated into Hong Kong culture over time, eroding the label's feeling of foreignness (cf. D. Wong, 2011). Future research could investigate these potential changes. 
Future research could also further explore how different identification labels interact. While our analysis sheds light on the fact that self-identified tongzhis often also describe themselves with other labels for sexual orientation minorities, it did not evaluate the strength of respondents' relative preferences among the labels that they use. Nor did we ask respondents to explain whether different labels apply at different times or under different circumstances. Future research should explore some of these questions about self-identification. It is also worth reiterating that our self-identification study was based on a convenience sample. This sampling method might have contributed to an overstatement or understatement of self-identification rates. We encourage future research to address this limitation by adopting a variety of different sampling methods. In addition, future research could expand beyond Hong Kong, investigating the prevalence of self-identifying as tongzhi in other parts of the world.

Importantly, our research underscores the importance of using other terms in addition to tongzhi in designing future studies. If researchers seek to study sexual orientation minorities in Hong Kong, materials for recruiting research subjects should be cast in terms that go beyond tongzhi. For example, a solicitation asking individuals to participate in a study about the tongzhi community risks recruiting only a particular subgroup of sexual orientation minorities in Hong Kong. Similar limitations might also exist in societies outside Hong Kong where tongzhi is used as an identifier.

With respect to public opinion, future research could explore whether replacing tongzhi with tongxinglianzhe, or vice versa, affects public opinion in ways that our split-ballot experiment could not detect. For example, using the term tongzhi in advocacy literature might make more of a difference than it did in our public opinion poll. It is possible, for example, that audiences are more likely to associate the term tongzhi with positive attributes when it appears in advocacy materials because of the term's historical linkages to political reform and solidarity. If this turns out to be true, the effectiveness of advocacy might be influenced by whether the term tongzhi is used.

Finally, as an overarching takeaway, this research note warns readers against analogizing too strongly between the tongzhi/tonxinglianzhe linguistic choice in Hong Kong and the "gay"/"homosexual" linguistic choice in AngloAmerican contexts. The analogy was weak in our analysis of self-identification and in our analysis of public opinion. Staying vigilant of the analogy's weakness would help researchers to think more clearly when developing future studies on the term tongzhi and the label's constituent populations.

\section{Funding}

This work was supported by a Williams Institute Small Research Grant, University of Hong Kong Small Project Funding Scheme Award [201007176315], Professional Development 
Funds from the University of North Carolina School of Law, and financial assistance from RTI International.

\section{Notes}

1. This research note presents transliterated Chinese terms in italics. We use Mandarin transliterations for the term tongzhi and terms with the root tongxinglian, as well as for a quote from Sun Yat-Sen. We use Mandarin transliterations in these contexts because the Mandarin versions have become popularized in English writing. For other Chinese terms, we use Cantonese transliterations because Cantonese is the dominant dialect in Hong Kong.

2. Clarification on this research note's own use of terminology: for concision, this note generally uses the English terms gay and gay and lesbian when referring to individuals who are attracted to the same sex. This note sometimes uses the more generic phrase sexual orientation minority to refer to individuals who are attracted to the same sex, even though it is a more cumbersome phrase, to underscore the fact that not all sexual orientation minorities self-identify with labels such as gay or tongzhi. When referring to a broader set of individuals including persons who are transgender or intersex, this note uses the phrase sexual minority as opposed to sexual orientation minority.

\section{References}

Atkinson, R., \& Flint, J. (2001). Accessing hidden and hard-to-reach populations: Snowball research strategies. Sociology at Survey Social Research Update, 33. Retrieved from http:// sru.soc.surrey.ac.uk/SRU33.pdf

Bucher, T., \& Raess, D. (2007). Discrimination, coming out, and job satisfaction of gay men in Switzerland: Results of a survey. In M. V. L. Badgett \& J. Frank (Eds.), Sexual orientation discrimination: An international perspective (pp. 194-205). New York, NY: Routledge.

Census and Statistics Department, The Government of the Hong Kong Special Administrative Region. (2012). 2011 Population statistics: Summary results. Retrieved from http://www.census2011.gov.hk/pdf/summary-results.pdf

陳沛冰 \& 潘柏林 [Chan, P. B., \& Poon, P. L.] (2013, November 10). 5200 人破紀錄走出來爭 平權 [A record-breaking 5200 people marched in support of equality]. Apple Daily, p. A1.

周華山 [Chou, W.] (1997). 後殖民同志 [Post-colonial tongzhi]. Hong Kong, China: Hong Kong Tongzhi Press.

Chou, W. (2001). Homosexuality and the cultural politics of tongzhi in Chinese societies. Journal of Homosexuality, 40(3-4), 27-46. doi:10.1300/J082v40n03_03

Glazer, E. M. (2010). Naming's necessity. Law \& Sexuality, 19, 166-169.

Hechkopf, K. (2010, February 11). Support for gays in the military depends on the question. CBS News. Retrieved from http://www.cbsnews.com/news/support-for-gays-in-the-mili tary-depends-on-the-question/

Ho, L. W. W. (2008). Speaking of same-sex subjects in China. Asian Studies Review, 32, 491509. doi:10.1080/10357820802492586

Home Affairs Bureau, The Government of the Hong Kong Special Administrative Region. (March 2006). Survey on public attitudes towards homosexuals. Retrieved from http://www. legco.gov.hk/yr05-06/english/panels/ha/papers/ha0310cb2-public-homosexuals-e.pdf

King, M. A. P. W. (2001). 女性 / 同志 / 女性主義與運動 [Female/Tongzhi /Feminism and movement]. In K. W. Chan, K. M. D. Wong, L. C. Leung, W. Y. J. Lee, \& C. W. Ho (Eds.), 
差異與平等——香港婦女運動的新挑戰 [Difference and equality: New challenges for the women's movement in Hong Kong] (pp. 77-92). Hong Kong: The Association for the Advancement of Feminism and Center for Social Policy Studies, Department of Applied Social Sciences, Hong Kong Polytechnic University.

Lam, M. (2003). 互吹不如單打 [Single minded, double entendre]. Hong Kong: Oxford University Press.

Lee, W. (2003). Kuaering queer theory. Journal of Homosexuality, 45(2-4), 147-170. doi:10.1300/J082v45n02_07

Martin, F. (2003). Situating sexualities: Queer representation in Taiwanese fiction, film, and public culture. Hong Kong: Hong Kong University Press.

McCabe, B. J., \& Heerwig, J. A. (2011). Reframing the marriage debate: Wording, context, and intensity of support for marriage and civil unions. International Journal of Public Opinion Research, 24, 429-449. doi:10.1093/ijpor/edr025

Morrison, M. A., \& Morrison, T. G. (2003). Development and validation of a scale measuring modern prejudice toward gay men and lesbian women. Journal of Homosexuality, 43(2), 15-37. doi:10.1300/J082v43n02_02

Peters, J. W. (2014, March 23). The decline and fall of the "H" word. New York Times, p. ST10.

Saad, L. (2005, May 20). Gay rights attitudes a mixed bag. Gallup News Service. Retrieved from http://www.gallup.com/poll/16402/gay-rights-attitudes-mixed-bag.aspx

Southern, D. A., Lewis, S., Maxwell, C. J., Dunn, J. R., Noseworthy, T. W., \& Corbett, G. (2008). Sampling "hard-to-reach" populations in health research: Yield from a study targeting Americans living in Canada. BMC Medical Research Methodology, 8, 57. doi:10.1186/1471-2288-8-57

To, C. (2003). Towards equality through legal reform: Empowerment and mobilization of the tongzhi (LGBT) community in Hong Kong. Journal of Gay \& Lesbian Social Services, 16, 65-74. doi:10.1300/J041v16n01_04

Tourangeau, R., \& Rasinski, K. A. (1988). Cognitive processes underlying context effects in attitude measurement. Psychological Bulletin, 103, 299-314. doi:10.1037/00332909.103.3.299

Vernon, K., \& Yik, A. (2012). Hong Kong LGBT climate study: Attitudes to and experiences of lesbian, gay, bisexual and transgender employees. Community Business. Retrieved from http://www.communitybusiness.org/lgbt/climatestudy.html

Weiss, M. L. (2007). We know who you are. We'll employ you. In M. V. L. Badgett \& J. Frank (Eds.), Sexual orientation discrimination: An international perspective (pp. 1-15). New York, NY: Routledge.

Wong, A. D. (2005). The reappropriation of tongzhi. Language in Society, 34, 763-793. doi:10.1017/S0047404505050281

Wong, A. D. (2008). The trouble with tongzhi: The politics of labeling among gay and lesbian Hongkongers. Pragmatics, 18, 277-301. doi:10.1075/prag.18.2.05won

Wong, D. (2011). Hybridization and the emergence of "gay" identities in Hong Kong and China. Visual Anthropology, 24, 152-170. doi:10.1080/08949468.2011.527810

Wright, L. W., Adams, H. E., \& Bernat, J. (1999). Development and validation of the homophobia scale. Journal of Psychopathology and Behavioral Assessment, 21, 337-347. doi:10.1177/1368430210387805 